\title{
BEARING CAPACITY IMPROVEMENT USING MICROPILES A CASE STUDY
}

\author{
G.L. Sivakumar Babu ${ }^{1}$, B. R.Srinivasa Murthy ${ }^{2}$, D.S. N. Murthy ${ }^{3}$, M.S. Nataraj ${ }^{4}$
}

\begin{abstract}
Micropiles have been used effectively in many applications of ground improvement to increase the bearing capacity and reduce the settlements particularly in strengthening the existing foundations. Frictional resistance between the surface of the pile and soil and the associated group/network effects of micropiles are considered as the possible mechanism for improvement. This paper deals with a case study in which micropiles of $100 \mathrm{~mm}$ diameter and $4 \mathrm{~m}$ long have been used to improve the bearing capacity of foundation soil and in the rehabilitation of the total building foundation system. The micropiles were inserted around the individual footings at inclination of $70^{\circ}$ with the horizontal. The actual design for retrofitting was based on the assumption that the vertical component of the frictional force between the soil and the micropile resists the additional load coming from the structure over and above the bearing capacity. The technique was successful and the structure did not show any signs of distress later. Detailed finite element analysis conducted validated the suggested treatment. The paper describes the case study, the method of treatment adopted in the field and the results of numerical analysis.
\end{abstract}

\footnotetext{
${ }^{1}$ Assistant Professor, Department of Civil Engineering, Indian Institute of Science, Bangalore - 560 012, India, gls@civil.iisc.ernet.in

${ }^{2}$ Professor, Department of Civil Engineering, Indian Institute of Science, Bangalore - 560012, India.

${ }^{3}$ Research Scholar, Department of Civil Engineering, Indian Institute of Science, Bangalore - 560 012, India.

${ }^{4}$ Professor, Department of Civil and Environmental Engineering, University of New Orleans, New Orleans, LA 70148-2212.
} 


\section{INTRODUCTION}

Micropiles are often used to improve the bearing capacity of the foundation against applied loading. In many cases, steel pipes of 50 to $200 \mathrm{~mm}$ diameters are used as micropiles. The strengthened ground acts as coherent mass and behaves remarkably well, capable of sustaining very high compressive loads at defined settlement or alternatively defined loads at reduced movement. Lizzi (1982) and Plumelle (1984) showed that micropiles create an in situ coherent composite reinforced soil system and the engineering behaviour of micropile-reinforced soil is highly dependent on the group and network effects that influence the overall resistance and shear strength of composite soil micropile system. Juran et al. (1999) presented an excellent state of art review, covering all the studies and contributions, on the state of practice using micropiles. Considerable information on single micropile design, evaluation of load bearing capacity, movement estimation models as well as effect of group and network effect have been covered in considerable detail. The authors also reviewed geotechnical design guidelines in different countries for axial, lateral load capacities and approach for movement estimation.

In India, in some circumstances steel pipes, coated wooden piles are used as costeffective options in improving the bearing capacity of foundation or restrict displacements to tolerable levels and similar uses in stabilization of slopes, strengthening of foundations are common. Sridharan and Murthy (1993) described a case study in which a ten-storeyed building, originally in a precarious condition due to differential settlement, was restored to safety using micropiles. Galvanized steel pipes of $100 \mathrm{~mm}$ diameter and $10 \mathrm{~m}$ long with bottom end closed with shoe, driven at an angle of $60^{\circ}$ with the horizontal were used and the friction between the pile and the soil was used as the design basis in evolving the remedial measures. A similar attempt was made in the present case study in which the bearing capacity of the existing foundation system of a building was restored to safety using micropiles.

\section{DETAILS OF THE CASE STUDY}

A two storeyed building rectangular in plan was constructed on a (loose sandy soil) filled up soil in a metropolitan city in India. The investigations revealed that the foundation soil is in relatively loose state (SPT values in the range of 6 to 8 ) and the results obtained from the laboratory tests indicated that the soil properties (effective stress parameters) viz., cohesion and friction angle can be taken as $\mathrm{c}^{\prime}=0$ and $\phi=25^{\circ}$ respectively and the bulk density $\left(\gamma_{b}\right)$ is in the range of $17 \mathrm{kN} / \mathrm{m}^{3}$. The foundations were designed to carry expected column load of $600 \mathrm{kN}$, considering that the safe bearing pressure of the soil is $120 \mathrm{kN} / \mathrm{m}^{2}$. Accordingly individual column footings of size $2.5 \mathrm{~m} \times 2.0 \mathrm{~m}$ were proposed. Above the foundation level, compacted soil (bulk density in the range of $20 \mathrm{kN} / \mathrm{m}^{3}$ ) was placed upto a height of $6.5 \mathrm{~m}$ to make up for the difference in level, which resulted in a further loading of $130 \mathrm{kN} / \mathrm{m}^{2}$ on the foundation. This aspect was not considered in the original design and as a result, 
plinth beam (at the foundation level) and tie beams at the middle level showed considerable distress in the form of cracks when the filling was nearing completion. Foundations supporting columns tilted out of line and further construction was difficult. Later on soil investigation showed that the safe bearing pressure considered originally in the design is higher and its actual value is around $70 \mathrm{kN} / \mathrm{m}^{2}$. It became necessary to restore the foundations and columns and hence micropiling has been chosen to strengthen the soil beneath the foundation. The treatment brought back the total foundation system to original requirements and was considered satisfactory. Fig. 1(a) shows the support system for retaining the soil outside the plinth beam and Fig. 1(b) shows the removal of the filled up soil before undertaking micropiling. Fig. 1(c) shows the micropiling in progress. The micropiling is done using a simple hammering system in which a mass of $2.6 \mathrm{kN}$ falls through a guide over a height of $1.5 \mathrm{~m}$.

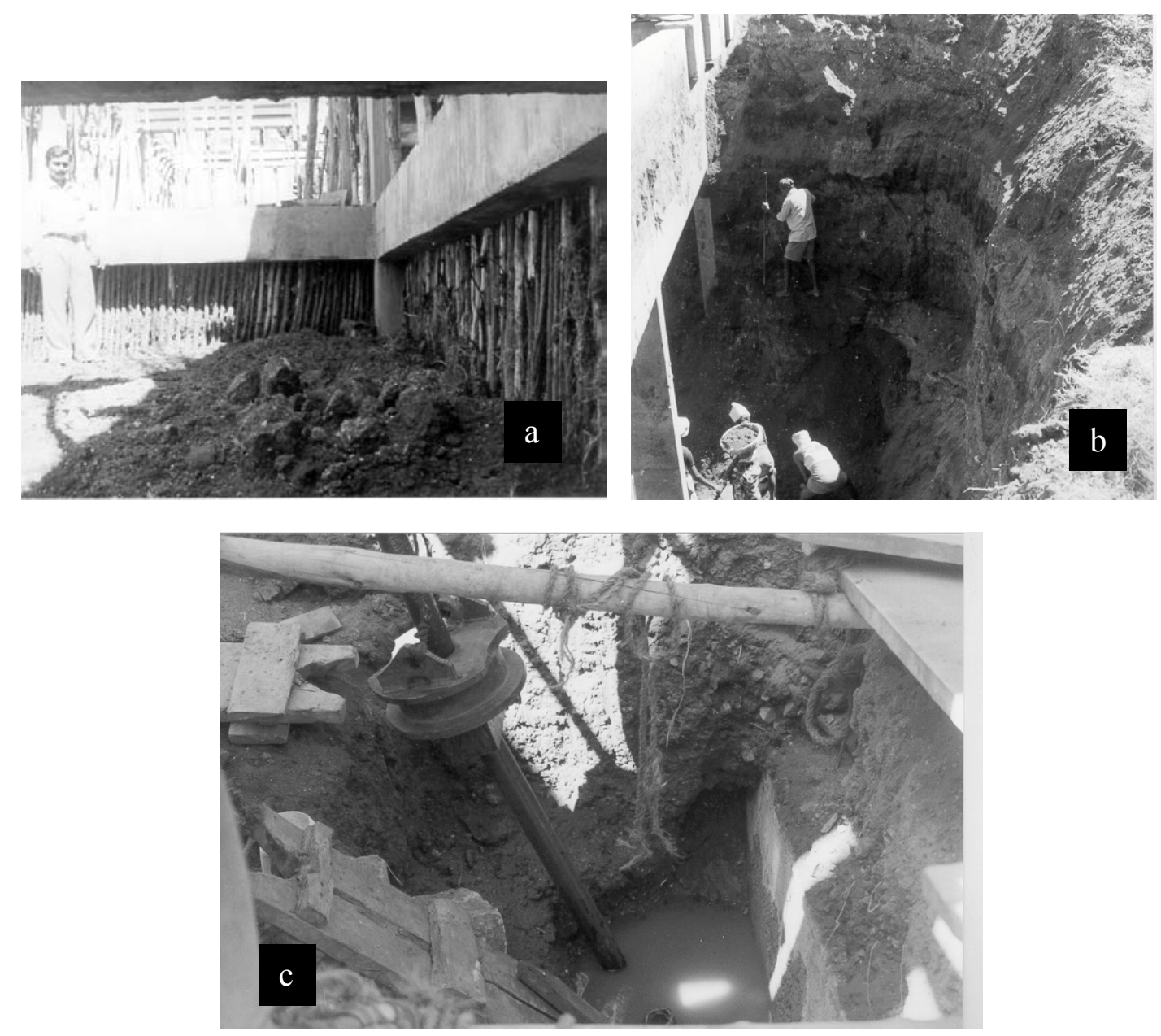

FIG. 1. (a) Stage of construction at the time of micropiling;

(b) Excavation of soil before implementing micropiling technique;

(c) Micropiling at the site 


\section{ANALYTICAL CONSIDERATIONS}

To design the micropile configuration to strengthen the foundation system the load on the footing from columns and filling are calculated and the required frictional resistance of the micropile system is evaluated. The calculations for a footing $(2.5 \mathrm{~m} \times 2.0 \mathrm{~m})$ are as follows.

The total load coming on the system $=$ column load + fill load

$$
=600 \mathrm{kN}+20 \mathrm{kN} / \mathrm{m}^{3} \times 6.5 \mathrm{~m} \times 2.5 \mathrm{~m} \times 2.0 \mathrm{~m}=1250 \mathrm{kN} \text {. }
$$

Required safe bearing pressure $=1250 / 2.5 \times 2=250 \mathrm{kPa}$

Safe load on the foundation system $=70 \mathrm{kPa} \times 2.5 \mathrm{~m} \times 2 \mathrm{~m}=350 \mathrm{kN}$

Additional load for which the micropile system is designed $=1250-350$

$$
=900 \mathrm{kN}
$$

The additional required frictional resistance of $900 \mathrm{kN}$ from the micropile system is derived based on considering an element of soil at the micropile-soil interface and integrating the element resistance over the entire length of micropile. The vertical component of the frictional resistance at the interface opposes the applied load on the footing. The frictional resistance offered by each micropile (of $4 \mathrm{~m}$ length and $100 \mathrm{~mm}$ diameter) is obtained from the component of earth pressure parallel to the axis of the pile. The additional resistance required to be carried by micropiles is calculated and the number of micropiles are arrived at based on the contribution of each micropile. The calculations indicate that $100 \mathrm{~mm}$ diameter micropiles spaced $200 \mathrm{~mm} \mathrm{c} / \mathrm{c}$ provide the frictional resistance required for desired level of bearing capacity improvement. Foundation treatment consisted of driving the micropiles at an angle of $70^{\circ}$ with the horizontal and close to the foundation as shown in Fig. 1(c). Plan and section of the structure and a schematic diagram of micropile system are shown in Figure 2. The remedial measures were implemented and the foundation has been retrofitted to the original requirements. While the solution that was suggested above was satisfactory in terms of immediate action of retrofitting, the case study also provided a good opportunity to examine the performance in terms of numerical analysis. Detailed finite element analysis has been conducted using PLAXIS to examine the above case study in terms of its overall performance.

\section{GEOMETRY MODEL AND NUMERICAL ANALYSIS}

PLAXIS is a 2-D finite element program, specially developed keeping in view geotechnical considerations. In the analysis, the footing is taken as beam element and assumed to behave as flexible and full footing of width $2.5 \mathrm{~m}$ is analysed as plane strain problem. Boundary effects are avoided, by keeping the ratio of mesh size to dimensions of footing at 12 . Standard boundary conditions (viz., imposing horizontal as well as vertical fixity to all nodes at bottom of mesh, and arresting horizontal movement of all nodes at both sides of mesh) are applied. The foundation soil was modeled as Mohr-Coulomb material and the micropile is modeled as elastic 
material. The properties used for the materials are given in Table 1. Micropiles (mild steel pipes with closed ends) of $100 \mathrm{~mm}$ diameter and $6 \mathrm{~mm}$ thick, spaced uniformly
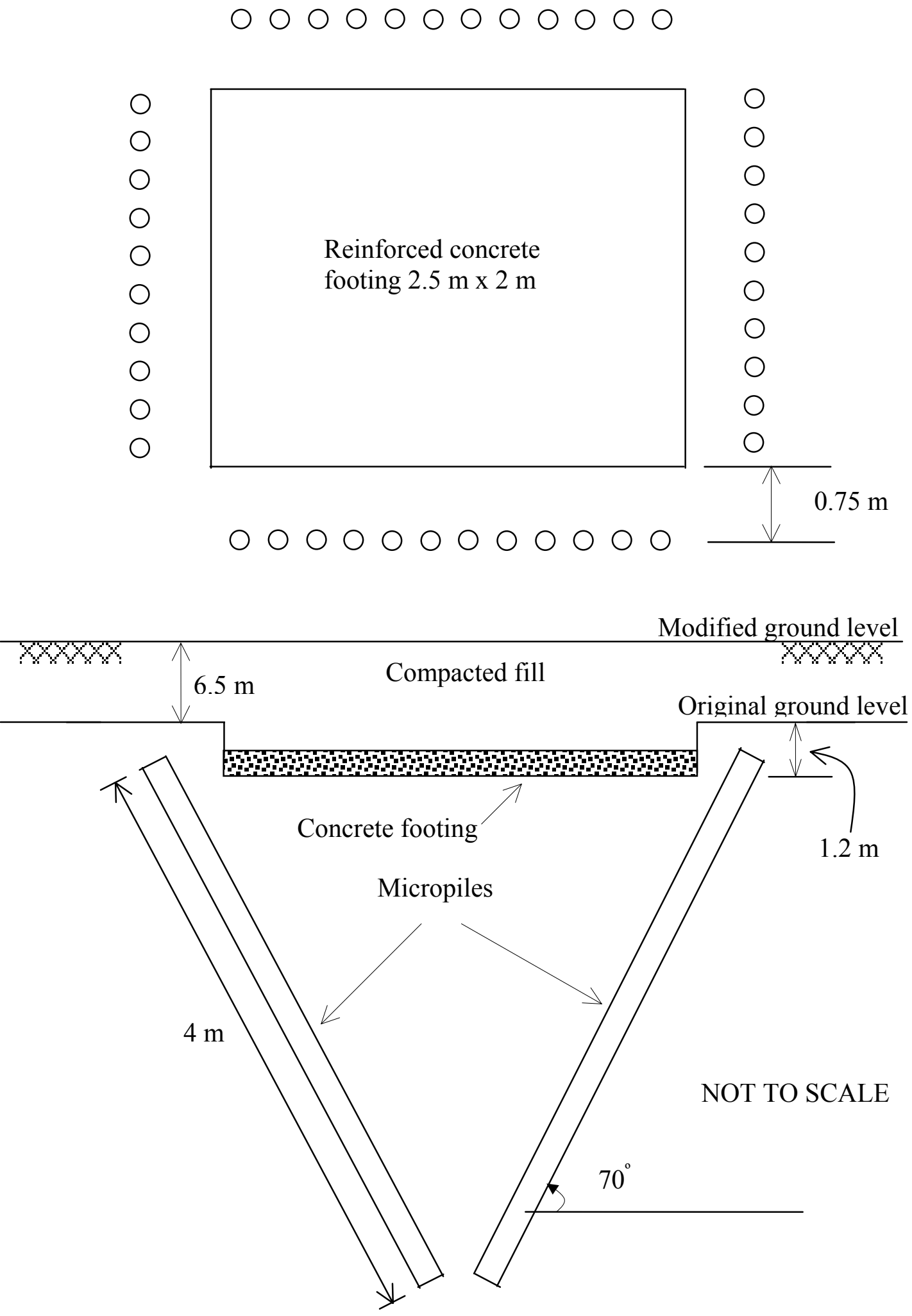

FIG. 2. Plan and cross sectional view of footing strengthened by micropile system 
in the third direction are considered for the analysis. Reducing 3D problems with regularly spaced piles to $2 \mathrm{D}$ problems involves averaging the effect in $3 \mathrm{D}$ over the distance between the elements. Donovan et al. (1984) suggests linear scaling of material properties as a simple and convenient way of distributing the discrete effect of elements over the distance between elements in a regularly spaced pattern. Similar approach was used by Tan et al. (2000) to examine nail-soil interaction behaviour. This approach was used in the present study. Since the micropiles were closely spaced at a distance of twice the diameter of the pile, it was assumed that densification of the soil surrounding the piles and the corresponding group effect is significant. Fig. 3 shows the finite element mesh along with the boundary conditions.

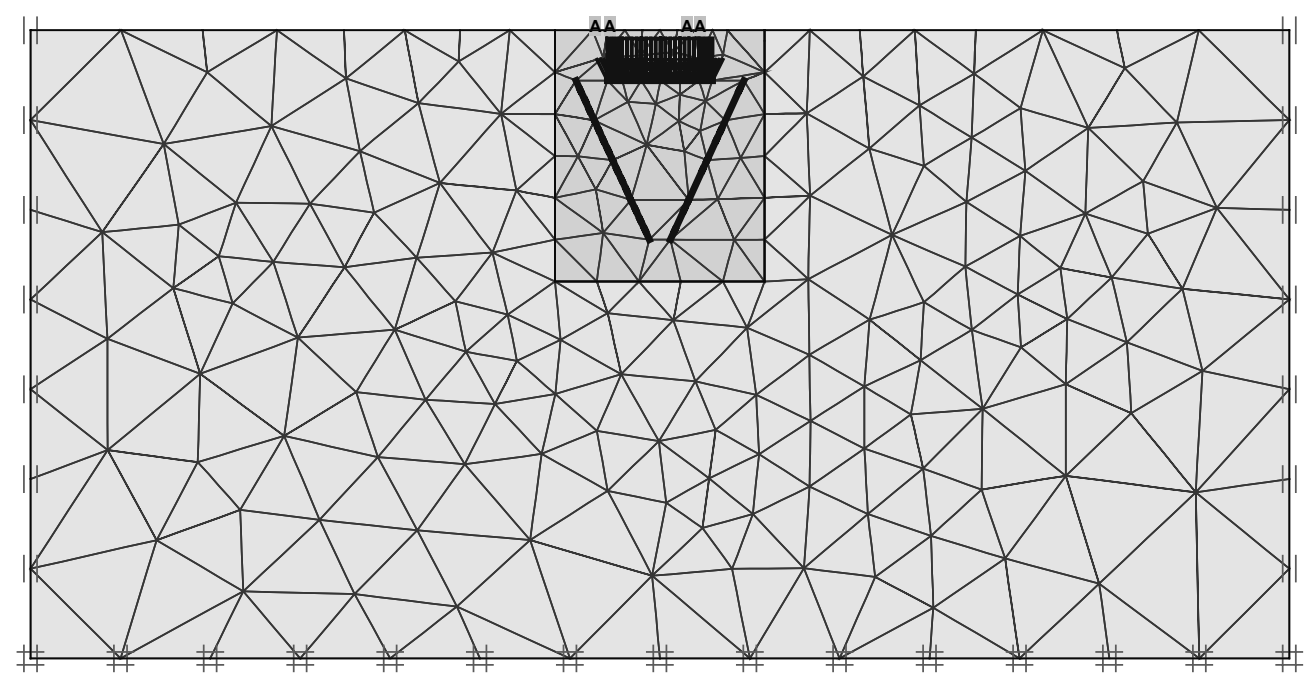

FIG. 3. Finite element mesh with boundary conditions

TABLE 1. Models and material properties used in the analysis

\begin{tabular}{|c|l|l|l|l|l|l|}
\hline \multicolumn{1}{|c|}{ Material } & \multicolumn{1}{|c|}{ Model } & $\begin{array}{c}\text { Cohesion } \\
\left(\mathrm{c}^{\prime}\right) \mathrm{kPa} \\
(1)\end{array}$ & \multicolumn{1}{|c|}{$(2)$} & \multicolumn{1}{c|}{$\phi^{\prime}\left(^{\circ}\right)$} & $\mathrm{E}(\mathrm{MPa})$ & \multicolumn{1}{|c|}{$\gamma_{\mathrm{b}}\left(\mathrm{kN} / \mathrm{m}^{3}\right)$} \\
\hline Loose sand & Mohr-Coloumb & 1 & 25 & $(5)$ & $(6)$ & \multicolumn{1}{c|}{$(7)$} \\
Dense sand & Mohr-Coloumb & 1 & 35 & 30 & 0.30 & 18 \\
Micropile & Elastic & - & - & $2.1 . \times 10^{5}$ & 0.30 & 20 \\
\hline
\end{tabular}

\section{RESULTS AND DISCUSSION}

Fig. 4 shows the load displacement response obtained from numerical simulations. Curve 1 is the load displacement curve obtained for the in-situ soil. The allowable bearing pressure corresponding to $25 \mathrm{~mm}$ is $66.8 \mathrm{kPa}$ and is close to the allowable bearing pressure of $70 \mathrm{kPa}$ considered in the revised design. Corresponding to $50 \mathrm{~mm}$, the allowable bearing pressure is $106.3 \mathrm{kPa}$. Curve 2 is the load displacement 
curve obtained corresponding to micropiles. The curve includes the densification effect, with properties of the sand in dense state indicated in Table 1 for the analysis.

Curve 2 shows the overall improvement in bearing capacity obtained. A value of $260 \mathrm{kPa}$ is obtained. Hence the numerical results obtained in the present study validate the ground improvement adopted in the field using micropiles.

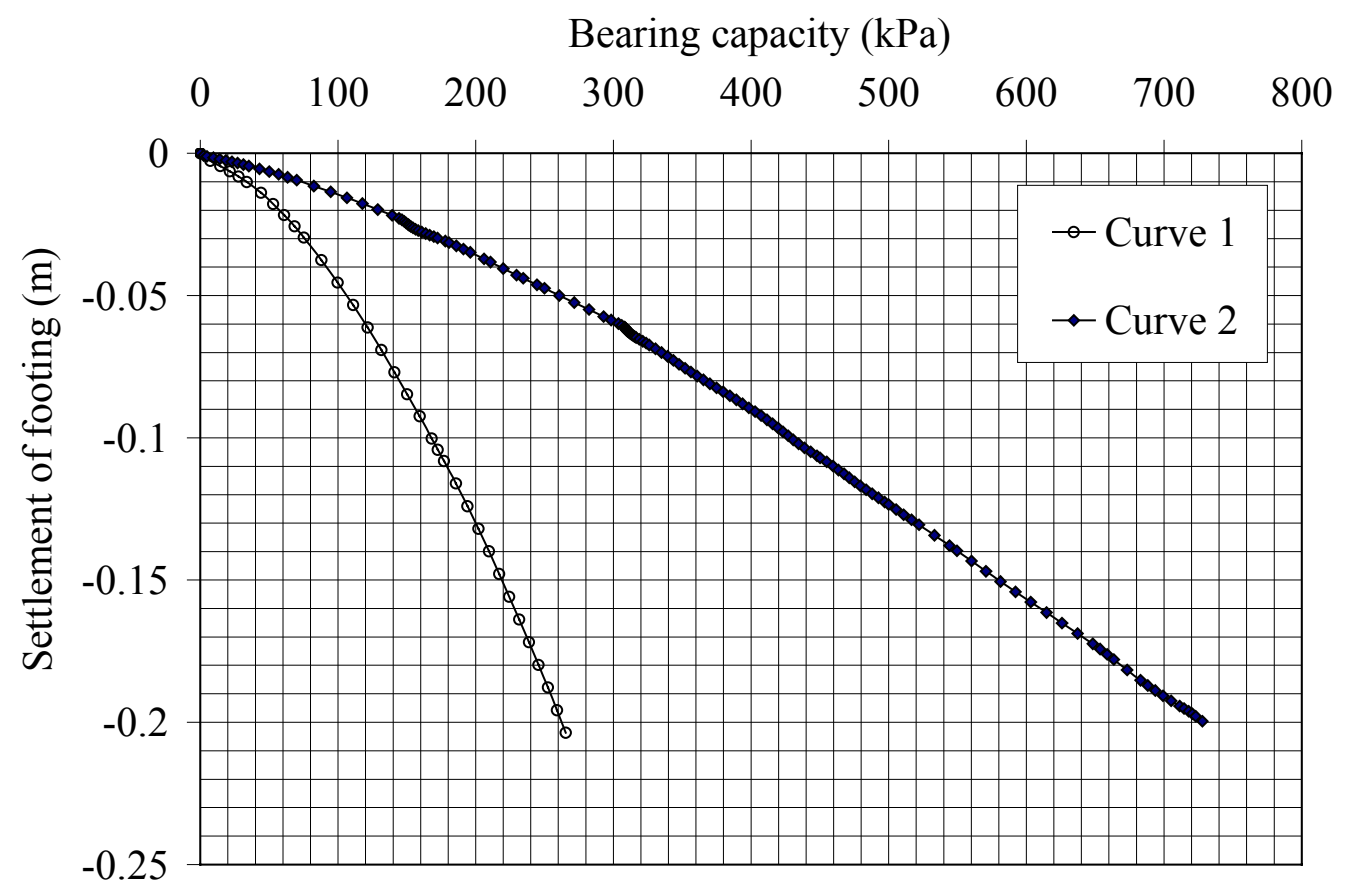

FIG. 4. Load-settlement curves with and without micropiling

\section{CONCLUDING REMARKS}

The paper describes a case study in which the bearing capacity of the foundation soil is improved using micropiles. Non-linear finite element analysis is carried out to examine the applicability and level of improvement obtained in the field. Densification of soil surrounding the micropiles and the frictional resistance between the micropiles and the foundation were given due consideration in the analysis. The results confirm that the methodology used was effective in obtaining the desired level of improvement. 


\section{REFERENCES}

Donovan, K., Pariseau, W.G., and Cepak, M. (1984). "Finite element approach to cable bolting in steeply digging VCR slopes". Geomechanics application in underground hardrock mining, 65-90.

Juran, I., Bruce, D.A., Dimillio, A., and Benslimane, A. (1999). "Micropiles: the state of practice. Part II: design of single micropiles and groups and networks of micropiles". Ground Improvement, 3, 89-110.

Lizzi, F. (1982). "The pali radice (root piles)". Symposium on soil and rock improvement techniques including geotextiles, reinforced earth and modern piling methods, Bangkok, D-3.

Plumelle, C. (1984). "Improvement of the bearing capacity of the soil by inserts of group and reticulated micropiles". International symposium on in-situ reinforcement of soils and rocks, Paris, 83-89.

Sridharan, A., and Murthy, B.R.S. (1993). "Remedial measures to building settlement problem". Proceedings of Third International conference on case histories in Geotechnical Engineering, St. Louis, Missouri, 221-224.

Tan, S.A., Luo, S.Q., and Yong, K.Y. (2000). "Simplified models for soil-nail lateral interaction". Ground Improvement, Vol. 4, No. 4, 141-152. 